\title{
Markers of inflammation and coagulation indicate a prothrombotic state in HIV-infected patients with long-term use of antiretroviral therapy with or without abacavir
}

\author{
Eefje Jong ${ }^{* 1,2}$, Joost CM Meijers ${ }^{3}$, Eric CM van Gorp ${ }^{1,4}$, C Arnold Spek ${ }^{5}$ and Jan W Mulder ${ }^{1}$
}

\begin{abstract}
Background: Abacavir (ABC) treatment has been associated with an increased incidence of myocardial infarction. The pathophysiological mechanism is unknown. In this study markers of inflammation and coagulation in HIV-infected patients using antiretroviral therapy with or without $A B C$ were examined to pinpoint a pathogenic mechanism. Given the important role of high sensitivity C-reactive protein (hsCRP) levels in predicting cardiovascular risk, patient groups were also analyzed according to hsCRP levels.

Methods: Patients treated with $A B C$ and a matched control group treated without $A B C$ were selected retrospectively. Vascular endothelial growth factor (VEGF) and markers of endothelial cell activation (von Willebrand factor (VWF), factor VIII), fibrin formation (fibrinogen, D-dimer, prothrombin fragment $1+2(F 1+2)$, endogenous thrombin potential (ETP)), anticoagulation markers (protein C and S, activated protein C sensitivity ratio (APCSr)) and inflammation markers (IL-6, hs(RP) were measured in citrated plasma.

Results: A total of 81 patients were included of whom 27 patients used an ABC-containing regimen and 54 used a non-ABC-containing regimen. Patient characteristics were not significantly different between the groups except for longer duration of use of the current antiretroviral regimen in the $A B C$ group $(p=0.01)$. The median time on $A B C$ was 68 months (interquartile range 59-80 months). No differences in coagulation and inflammation markers according to ABC use were observed. For the whole patient group elevated VWF and $\mathrm{F} 1+2$ levels were observed in $23 \%$ and $37 \%$, respectively. Compared to the reference ranges for the general population increased APCsr was found in $79 \%$ and lower protein C and VEGF levels in $40 \%$ and $43 \%$, respectively. Patients in the high-risk category for cardiovascular disease with hsCRP levels $>3 \mathrm{mg} / \mathrm{L}$ had significantly higher fibrinogen, D-dimer, F1+2 and ETP levels compared to patients from the low-risk category with hsCRP levels $<1 \mathrm{mg} / \mathrm{L}$.

Conclusion: HIV-infected patients using ABC showed no specific abnormalities in coagulation or inflammation markers that might explain the increased risk of myocardial infarction. For the whole group, regardless of $A B C$ use, evidence of a prothrombotic state was observed. Thirty-three percent of patients with long-term use of antiretroviral treatment had hsCRP levels above $3 \mathrm{mg} / \mathrm{L}$, which is strongly associated with cardiovascular disease in HIV-uninfected individuals.
\end{abstract}

\section{Background}

The Data Collection on Adverse Events of Anti-HIV Drugs (D:A:D) study, an observational study in over $30.000 \mathrm{HIV}-1$ infected individuals, reported an increased

* Correspondence: eefje.jong@s|z.nl

${ }^{1}$ Department of Internal Medicine, Slotervaart Hospital, Amsterdam, the Netherlands

Full list of author information is available at the end of the article risk of myocardial infarction in HIV-infected patients with current or recent exposure to abacavir $(A B C)$ and didanosine (ddI)[1]. The SMART study and a Danish study by Obel et al. observed a similar association with severe cardiovascular disease [2,3]. The increased risk was evident while patients were actually receiving the drugs up to 6 months after stopping them. However, the 
ACTG study group and GlaxoSmithKline-sponsored clinical trials observed no association between $A B C$ use and increased risk of myocardial infarction or severe cardiovascular disease $[4,5]$. As possible pathogenic mechanisms endothelial dysfunction, a proinflammatory state with plaque rupture and subsequent thrombosis and platelet hyperreactivity have been suggested [6-9]. Earlier studies focussed on markers of inflammation and coagulation before and after initiation of an $\mathrm{ABC}$-containing regimen. No changes in high sensitivity $\mathrm{C}$-reactive protein (hsCRP), interleukin (IL)-6, soluble vascular adhesion molecule and D-dimer levels were observed $[8,9]$. In a recent study increases in metallopeptidase 9 , myeloperoxidase and hsCRP levels as markers of cardiovascular risk were observed in a longitudinal cohort of virologi- cally suppressed patients switching to $\mathrm{ABC}[10]$. Earlier studies in non-HIV infected individuals described elevated high sensitivity $\mathrm{C}$-reactive protein (hSCRP) levels as the most important factor in predicting cardiovascular risk [11]. Hsue et al. demonstrated lower flow-mediated vasodilatation as marker of endothelial dysfunction in patients on $A B C$ [6]. Vascular endothelial growth factor (VEGF) could be an inducible factor in the process of endothelial dysfunction, but has not been studied in this setting. Anti-angiogenic properties through an inhibitory effect on VEGF were attributed to protease inhibitors in glioblastoma cells and treatment of Kaposi sarcoma $[12,13]$. Inhibition of VEGF was associated with thrombotic microangiopathy of the kidney [14].

Table 1: Patient characteristics according to $A B C$ use

\begin{tabular}{|c|c|c|}
\hline & ABC-containing regimen & Non-ABC-containing regimen \\
\hline Number of patients ( $\%$ male) & $27(89)$ & $54(89)$ \\
\hline Age (years) & $48 \pm 11$ & $47 \pm 10$ \\
\hline \multicolumn{3}{|l|}{ Ethnicity } \\
\hline Caucasian (\%) & $23(85)$ & $43(80)$ \\
\hline African-American (\%) & $1(4)$ & $4(7)$ \\
\hline Asian (\%) & $2(7)$ & $4(7)$ \\
\hline Other (\%) & $1(4)$ & $3(6)$ \\
\hline Current smoker (\%) & $13(48)$ & $19(35)$ \\
\hline Chronic hepatitis C infection (\%) & $2(7)$ & $4(7)$ \\
\hline Chronic hepatitis B infection (\%) & $1(4)$ & $1(2)$ \\
\hline History of cardiovascular event (\%) & $1(4)$ & - \\
\hline Total duration of cART use (months) & $116(85-129)^{*}$ & $91(33-121)$ \\
\hline Total time on $\mathrm{ABC}$ (months) & $68(59-80)$ & - \\
\hline \multicolumn{3}{|l|}{ CART regimen } \\
\hline $\mathrm{ABC}+$ other NRTI (\%) & $11(41)$ & - \\
\hline $\mathrm{ABC}+\mathrm{PI}(\%)$ & $7(26)$ & - \\
\hline$A B C+N N R T I(\%)$ & $9(33)$ & - \\
\hline non-ABC + PI (\%) & - & $27(50)$ \\
\hline non-ABC + NNRTI (\%) & - & $27(50)$ \\
\hline CD4 cell count (cells/mm3) & $490(310-770)$ & $530(300-720)$ \\
\hline HIV viral load <40 copies/ml (\%) & $23(85)$ & $46(85)$ \\
\hline $\begin{array}{l}\text { Duration HIV viral load < } 40 \text { copies/ml } \\
\text { (months) }\end{array}$ & $90(72-113)$ & $68(22-120)$ \\
\hline Total cholesterol (mmol/L) & $5.0 \pm 0.9$ & $5.0 \pm 1.0$ \\
\hline Triglycerides (mmol/L) & $2.5 \pm 1.9$ & $2.2 \pm 1.7$ \\
\hline Non-fasting glucose (mmol/L) & $6.1 \pm 1.2$ & $5.9 \pm 1.5$ \\
\hline Use of antihypertensive drugs (\%) & $2(7)$ & $7(13)$ \\
\hline Use of statins (\%) & $7(26)$ & $6(11)$ \\
\hline Use of oral antidiabetics (\%) & $1(4)$ & $0(-)$ \\
\hline
\end{tabular}

CART = combined antiretroviral therapy; $\mathrm{ABC}=$ abacavir; $\mathrm{NRTI}=$ nucleoside reverse transcriptase inhibitor; $\mathrm{NNRTI}=$ non-nucleoside reverse transcriptase inhibitor; $\mathrm{PI}=$ protease inhibitor $* p<0.05$ 
In the current study markers of inflammation and coagulation in HIV-infected patients on present combined antiretroviral therapy (cART) with or without $A B C$ were compared in order to pinpoint a pathogenic mechanism for the increased risk of myocardial infarction in patients using $\mathrm{ABC}$. Given the important role of hsCRP levels in predicting cardiovascular risk, patient groups were also analyzed according to hsCRP levels.

\section{Methods}

\section{Study population}

All patients using an $\mathrm{ABC}$-containing regimen were retrospectively selected from the Slotervaart HIV cohort study, a prospective cohort study on markers of coagulation and inflammation in HIV-infected patients. The control group existed of HIV-infected patients participating in the Slotervaart HIV cohort study who were using cART without $\mathrm{ABC}$ including a protease inhibitor (PI) or a non-nucleoside transcriptase inhibitor (NNRTI) and were matched for age, sex, CD4 cell count and HIV viral load. Patients using ddI were excluded. Blood was taken at a follow-up visit in the outpatient clinic, when the patient showed no signs of active infection.

\section{Laboratory testing}

PT, aPTT and markers of endothelial cell activation (von Willebrand factor (vWF), VEGF)), fibrin formation (fibrinogen, D-dimer, prothrombin fragment $1+2(\mathrm{~F} 1+2)$, endogenous thrombin potential (ETP)), anticoagulation (protein $\mathrm{C}$ and $\mathrm{S}$, activated protein $\mathrm{C}$ sensitivity ratio (APCsr)) and inflammation (IL-6, hsCRP) were measured in citrated plasma as described before[15] VEGF, hsCRP and IL- 6 were assayed by ELISA (R\&D Systems Europe Ltd., Abingdon, UK). The ETP assay is a global coagulation assay that measures thrombin generation in tissue factor triggered platelet-poor plasma, providing an estimation of the potential to form a clot under (patho)physiological conditions. The ETP was determined with a Calibrated Automated Thrombogram (CAT). The CAT assays the generation of thrombin in clotting plasma using a microtiter plate reading fluorometer (Fluoroskan Ascent, ThermoLab systems, Helsinki, Finland) and Thrombinoscope software (Thrombinoscope BV, Maastricht, the Netherlands) as previously described [16]. CD4 cell counts were analyzed using flow cytometric techniques (Becton Dickinson, USA). HIV RNA levels were quantified using the COBAS Ampliprep and COBAS TaqMan (Roche Diagnostics, Almere, The Netherlands).

\section{Statistical methods}

Continuous variables were expressed as median values (interquartile range (IQR)) for not normally distributed variables and means (standard deviation) for normally

Table 2: Results of laboratory parameters according to $A B C$ use*

\begin{tabular}{|c|c|c|c|}
\hline Laboratory parameter & ABC-containing regimen $(n=27)$ & Non-ABC-containing regimen $(n=54)$ & $\begin{array}{l}\text { Reference range for } \\
\text { the general population }\end{array}$ \\
\hline PT (sec) & $11.5(11.0-12.0)$ & $11.7(11.1-12.2)$ & $10.7-12.9$ \\
\hline Fibrinogen $(\mathrm{g} / \mathrm{L})$ & $2.9(2.5-3.2)$ & $2.7(2.3-3.5)$ & $1.9-4.0$ \\
\hline vWF (\%) & $112(89-185)$ & $124(100-168)$ & $50-150$ \\
\hline D-dimer (mg/L) & $0.4(0.2-0.4)$ & $0.2(0.2-0.4)$ & $<1.00$ \\
\hline $\mathrm{F} 1+2(\mathrm{pmol} / \mathrm{L})$ & $213(177-276)$ & $196(122-257)$ & $53-271$ \\
\hline PC (\%) & $115(98-138)$ & $116(98-127)$ & $70-120$ \\
\hline PS total $(\%)$ & $105(90-115)$ & $104(86-114)$ & $58-130$ \\
\hline PS free $(\%)$ & $81(68-102)$ & $82(70-99)$ & $63-137$ \\
\hline ETP (nM.min) & 1844 (1620-2052) & 1740 (1602-1959) & $1155-2606$ \\
\hline ETP peak (nM) & $381(345-394)$ & $374(339-414)$ & $194-503$ \\
\hline APCsr & $2.2(1.7-4.0)$ & $2.5(1.9-3.3)$ & $<1.6$ \\
\hline VEGF (pg/ml) & $37(27-47)$ & $33(23-51)$ & $31-86$ \\
\hline $\mathrm{IL}-6(\mathrm{pg} / \mathrm{ml})$ & $<1.0(-)$ & $<1.0(-)$ & $<4.0$ \\
\hline $\mathrm{hsCRP}(\mathrm{mg} / \mathrm{L})$ & $1.6(0.4-5.3)$ & $1.6(0.5-3.3)$ & $<1.0$ \\
\hline
\end{tabular}

*The results are shown as median values (interquartile range)

$\mathrm{ABC}=$ abacavir; $\mathrm{fVIII}=$ factor $\mathrm{VIII} ; \mathrm{VWF}=$ von Willebrand factor; $\mathrm{F} 1+2=$ prothrombin fragment $1+2 ; \mathrm{PC}=$ protein $\mathrm{C} ; \mathrm{PS}=$ protein $\mathrm{S} ; \mathrm{ETP}=$ endogenous thrombin potential; $\mathrm{APCsr}=$ activated protein $\mathrm{C}$ sensitivity ratio; $\mathrm{VEGF}=$ vascular endothelial growth factor; $\mathrm{hsCPR}=\mathrm{high}-$ sensitivity C-reactive protein 
distributed variables. Categorical variables were expressed as counts and percentages. Coagulation and inflammation markers were compared between patient groups with and without $\mathrm{ABC}$. Besides, all patients were stratified in low-risk, average-risk and high-risk categories for cardiovascular disease according to their hsCRP levels independent of $A B C$ use. hsCRP levels of $<1.0 \mathrm{mg} /$ $\mathrm{L}$ indicated low-risk, hsCRP levels of $1.0-3.0 \mathrm{mg} / \mathrm{L}$ indicated average-risk and hsCRP levels $>3.0 \mathrm{mg} / \mathrm{L}$ indicated high-risk for cardiovascular disease [11]. Normally distributed parameters were compared using a two-sample independent $\mathrm{t}$-test. For not normally distributed parameters a Mann-Whitney test was used. Dichotomous variables were compared using a Chi-squared test. Categorical variables were analyzed using a Kruskall Wallis test with Bonferroni correction for multiple testing. A p-value of $<.05$ was considered significant. The calculations were performed using the Statistical Package for Social Sciences (SPSS Inc., Chicago, Illinois, version 16.0) software package.

\section{Results}

A total of 81 patients were identified with a median age of 47 years (26-73 years), of whom $89 \%$ were male and $82 \%$ Caucasian. Twenty-seven patients were using an ABCcontaining regimen and 54 a non- $\mathrm{ABC}$-containing regimen. In both treatment groups $85 \%$ of patients were virologically suppressed for many years. One patient had a history of an ischemic cerebrovascular accident while on $A B C$ before inclusion in the study. No patients with a documented myocardial infarction were reported. The patient characteristics stratified according to use of $A B C$ are shown in Table 1. There were no significant differences between the groups except for longer duration of cART use in the patients treated with ABC ( $\mathrm{p}=0.01)$. The median time on $\mathrm{ABC}$ was 68 months (IQR 59-80 months).

The median (IQR) of the laboratory markers according to $A B C$ use are shown in Table 2. Table 3 shows the percentage of patients with a test result outside the reference range. No significant differences in laboratory parameters were observed between patients treated with and without

Table 3: Number (\%) of patients with laboratory parameters outside the reference range

\begin{tabular}{|c|c|c|c|}
\hline Laboratory parameter & Total group $(n=81)$ & ABC-containing regimen $(n=27)$ & Non-ABC-containing regimen $(n=54)$ \\
\hline Prolonged aPTT & $2(3)$ & $0(-)$ & $2(4)$ \\
\hline Prolonged PT & $5(6)$ & $1(4)$ & $4(7)$ \\
\hline Elevated fibrinogen & $11(14)$ & $3(11)$ & $6(11)$ \\
\hline Elevated FVIII & $14(17)$ & $6(22)$ & $8(15)$ \\
\hline Elevated vWF & $19(23)$ & $7(26)$ & $12(22)$ \\
\hline Elevated D-dimer & $3(4)$ & $2(7)$ & $1(2)$ \\
\hline Elevated F1+2 & $30(37)$ & $10(37)$ & $20(37)$ \\
\hline Decreased PC & $32(40)$ & $11(41)$ & $21(39)$ \\
\hline Decreased total protein $\mathrm{S}$ & $6(7)$ & $3(11)$ & $3(6)$ \\
\hline Decreased free protein $\mathrm{S}$ & $11(14)$ & $4(15)$ & $7(13)$ \\
\hline Increased ETP & $0(-)$ & $0(-)$ & $0(-)$ \\
\hline Increased peak ETP & $2(3)$ & $0(-)$ & $2(4)$ \\
\hline Increased APCsr & $64(79)$ & $21(78)$ & $43(80)$ \\
\hline Decreased VEGF & $4(5)$ & $2(7)$ & $2(4)$ \\
\hline Elevated IL-6 & $35(43)$ & $10(37)$ & $25(46)$ \\
\hline \multicolumn{4}{|l|}{ hsCRP category } \\
\hline Low risk (hsCRP $<1 \mathrm{mg} / \mathrm{L}$ ) & $28(35)$ & $9(33)$ & $19(35)$ \\
\hline $\begin{array}{l}\text { Average risk (hsCRP 1-3 } \\
\mathrm{mg} / \mathrm{L} \text { ) }\end{array}$ & $24(30)$ & $6(22)$ & $18(33)$ \\
\hline High risk ( $\mathrm{hsCRP}>3 \mathrm{mg} / \mathrm{L}$ ) & $27(33)$ & $10(37)$ & $17(32)$ \\
\hline Missing & $2(3)$ & $2(7)$ & - \\
\hline
\end{tabular}

$\mathrm{ABC}=$ abacavir fVIII = factor VIII; $\mathrm{VWF}=$ von Willebrand factor; $\mathrm{F} 1+2=$ prothrombin fragment $1+2 ; \mathrm{PC}=$ protein $\mathrm{C} ; \mathrm{PS}=$ protein $\mathrm{S} ; \mathrm{ETP}=$ endogenous thrombin potential; $\mathrm{APCsr}=$ activated protein $\mathrm{C}$ sensitivity ratio; $\mathrm{VEGF}=$ vascular endothelial growth factor; hsCRP $=$ high sensitivity C-reactive protein 
$\mathrm{ABC}$. However, for the whole group, we found elevated vWF levels in $23 \%$ of patients, elevated F1+2 levels in 37\% of patients, while APCsr was increased in $79 \%$ of patients compared to the reference ranges for the general population. Low PC levels were observed in $40 \%$ and decreased VEGF levels in $43 \%$ of patients. IL-6 levels were low for the whole group. When stratified into risk categories for cardiovascular disease according to hsCRP levels, 28 (35\%) patients fell in the low-risk category, $24(30 \%)$ in the average-risk category and 27 (33\%) in the high-risk category for cardiovascular disease. Patients on $A B C$ were evenly distributed between the various categories. In Table 4 mean and median values for demographic and laboratory parameters are depicted grouped by risk category. Significantly higher fibrinogen, D-dimer, $\mathrm{F} 1+2$ and ETP levels were observed when the high-risk category was compared to the low-risk category. When only patients using $A B C$ were selected this finding was confirmed for fibrinogen and D-dimer levels.

\section{Discussion}

We studied markers of inflammation and coagulation in HIV-infected patients treated with and without $A B C$ to pinpoint a pathogenic mechanism for the increased risk of myocardial infarction in patients with current or recent (up to 6 months) exposure to $A B C$. Previous studies primarily focussed on markers of coagulation and inflammation before and after initiation of an ABC-containing regimen. In these studies changes in hsCRP, IL-6, soluble vascular adhesion molecule and D-dimer levels were not significantly different between patient groups treated with or without $\mathrm{ABC}[8,9]$. We focussed on HIVinfected patients with long-term use of cART. Our findings showed no differences in inflammation and coagula-

Table 4: Demographic and laboratory parameters stratified to risk category based on hsCRP levels

\begin{tabular}{|c|c|c|c|}
\hline & $\begin{array}{l}\text { Low risk category } \\
\text { (hsCRP }<1 \mathrm{mg} / \mathrm{L} \text { ) }\end{array}$ & $\begin{array}{l}\text { Average risk category } \\
\text { (hsCRP 1-3 mg/L) }\end{array}$ & $\begin{array}{l}\text { High risk category } \\
\text { (hsCRP >3 mg/L) }\end{array}$ \\
\hline Number of patients & 28 & 24 & 27 \\
\hline Age (years) & $47.8( \pm 10.2)$ & $48.4( \pm 11.6)$ & $48.2( \pm 9.1)$ \\
\hline Duration of cART use (months) & $76(25-125)$ & $116(42-124)$ & $111(26-127)$ \\
\hline CD4 cell count (cells/mm3) & $390(300-765)$ & $460(340-805)$ & $500(288-633)$ \\
\hline HIV viral load $<40$ copies/mI (\%) & $24(86)$ & $21(88)$ & $22(81)$ \\
\hline Total cholesterol (mmol/L) & $4.9( \pm 1.0)$ & $5.7( \pm 0.9)$ & $5.1( \pm 0.8)$ \\
\hline Triglycerides (mmol/L) & $2.2( \pm 1.9)$ & $2.7( \pm 2.0)$ & $2.0( \pm 1.4)$ \\
\hline Non-fasting glucose ( $\mathrm{mmol} / \mathrm{L})$ & $5.9( \pm 1.1)$ & $5.9( \pm 1.1)$ & $6.1( \pm 1.6)$ \\
\hline Patients on $A B C(\%)$ & $9(32)$ & $7(29)$ & $11(41)$ \\
\hline aPTT (sec) & $31.5( \pm 3.3)$ & $32.2( \pm 3.1)$ & $30.5( \pm 3.2)$ \\
\hline PT (sec) & $11.8( \pm 0.9)$ & $11.7( \pm 0.6)$ & $11.5( \pm 0.8)$ \\
\hline Fibrinogen $(\mathrm{g} / \mathrm{L})$ & $2.4(2.1-2.6)$ & $2.8(2.3-3.2)^{*}$ & $3.5(2.8-4.1)^{*}$ \\
\hline FVIII (\%) & $115(102-145)$ & $122(105-172)$ & $122(100-158)$ \\
\hline vWF (\%) & $124(92-160)$ & $123(101-177)$ & $114(98-188)$ \\
\hline D-dimer (mg/L) & $0.2(0.2-0.3)$ & $0.2(0.2-0.3)$ & $0.3(0.2-0.5)^{*}$ \\
\hline $\mathrm{F} 1+2(\mathrm{pmol} / \mathrm{L})$ & $175(151-229)$ & $210(163-269)$ & $219(197-305)^{*}$ \\
\hline PC (\%) & $114( \pm 25.7)$ & $111( \pm 20.6)$ & $120( \pm 20.9)$ \\
\hline PS total (\%) & $96( \pm 18.7)$ & $104( \pm 14.5)$ & $105( \pm 20.8)$ \\
\hline PS free (\%) & $87( \pm 16.8)$ & $93( \pm 24.8)$ & $82( \pm 26.0)$ \\
\hline ETP (nM.min) & $1663( \pm 274)$ & $1803( \pm 237)^{*}$ & $1913( \pm 336)^{*}$ \\
\hline ETP peak (nM) & $371(328-401)$ & $371(341-407)$ & $386(364-417)$ \\
\hline APCsr & $2.9(2.1-3.7)$ & $2.0(1.7-2.9)^{*}$ & $2.6(1.6-4.4)$ \\
\hline VEGF (pg/ml) & $30(24-42)$ & $30(26-52)$ & $37(27-53)$ \\
\hline IL-6 (pg/ml) & $1.0(-)$ & $1.0(-)$ & $1.0(-)$ \\
\hline
\end{tabular}

hsCRP = high-sensitivity C-reactive protein; $\mathrm{VVIII}=$ factor; $\mathrm{VWF}=$ von Willebrand factor; F1+2 = prothrombin fragment $1+2 ; \mathrm{PC}=$ protein C; $\mathrm{PS}$ $=$ protein $\mathrm{S} ; \mathrm{ETP}=$ endogenous thrombin potential; $\mathrm{APCsr}=$ activated protein $\mathrm{C}$ sensitivity ratio; VEGF = vascular endothelial growth factor ${ }^{*} p<0.05$ (after Bonferroni correction for multiple testing) 
tion markers between HIV-infected patients treated with long-term cART with or without ABC.

In the current study, we hypothesized that VEGF, an important factor in the repair system of endothelial injury, might play a pathogenic role. VEGF is associated with angiogenesis, chemotaxis of macrophages and granulocytes, and vasodilatation. Anti-angiogenic properties through an inhibitory effect on VEGF were attributed to PIs in glioblastoma cells and treatment of Kaposi sarcoma $[12,13]$. No differences in VEGF levels were observed between patients on an $\mathrm{ABC}$-containing regimen or a non-ABC-containing regimen. Nevertheless, VEGF levels were reduced in a significant proportion of the whole group of HIV-infected patients with long-term use of cART. This might be suggestive of a decrease in angiogenesis and endothelial repair. Use of PIs was evenly distributed between the two groups. No difference in VEGF levels was observed between patients using PIs or NNRTIs.

For the whole group evidence of endothelial cell activation, increased fibrin formation and decreased anticoagulation was observed compatible with a prothrombotic state. Furthermore, 33\% of the patients with long term use of cART with undetectable or very low levels of viral replication had hsCRP levels $>3 \mathrm{mg} / \mathrm{L}$, which are strongly linked to cardiovascular disease in HIV-uninfected individuals [11]. IL-6 levels were low for the whole group indicating low levels of inflammation. A trend was observed of higher hsCRP levels in both the ABC- and non-ABC group with longer duration of cART use. Earlier Pallela et al. reported an increase in hsCRP levels between baseline and index visits (mean 4.2 years apart) in HIV-infected women on cART with or without ABC [9]. Higher hsCRP levels in HIV-infected individuals were also reported by Hsue et al. when comparing HIVinfected individuals to the general population [17]. In our study the high-risk category with hsCRP levels $>3 \mathrm{mg} / \mathrm{L}$ showed increased fibrinogen, D-dimer, F1+2 and ETP levels indicating a prothrombotic state. No differences in markers of endothelial cell activation or anticoagulation according to hsCRP levels were observed.

The significant difference in duration of cART use could be a limitation of the study. If as hypothesized, $A B C$ use would be associated with abnormal inflammation and coagulation markers this would probably be accentuated by longer duration of $\mathrm{ABC}$ use. Actually, no differences were observed between the two study groups. Furthermore, by using a cross-sectional design no conclusions could be drawn regarding the association of the observed inflammation and coagulation abnormalities and cardiovascular events.

\section{Conclusion}

HIV-infected patients using $A B C$ showed no specific abnormalities in coagulation or inflammation markers that might explain the increased risk of myocardial infarction. For the whole patient group, regardless of $A B C$ use, evidence of a prothrombotic state was observed. Thirty-three percent of patients with longterm use of cART and undetectable viral load, had hsCRP levels above $3 \mathrm{mg} / \mathrm{L}$, which is strongly associated with cardiovascular disease in HIV-uninfected individuals.

\section{Competing interests \\ EJ serves as a medical consultant to Gilead Medical Sciences.}

\section{Authors' contributions}

EJ, ECMG and JWM participated in the design of the study. JCMM carried out the coagulation assays. CAS carried out the hsCRP and IL-6 assays. EJ drafted the manuscript with input from the other authors. All authors read and approved the final manuscript.

\section{Acknowledgements}

Jiri Wagenaar contributed to conception of the study. We thank Liliane van Bellet and Esther Oudmaijer for the acquisition of patient data and Olga Ternede and Monique de Rijk for processing of the blood samples. Majon Muller, MD, PhD, provided support with the statistical analysis.

\section{Author Details}

1Department of Internal Medicine, Slotervaart Hospital, Amsterdam, the Netherlands, ${ }^{2}$ Department of Infectious Diseases, University Medical Center, Utrecht, the Netherlands, ${ }^{3}$ Department of Experimental Vascular Medicine, Academic Medical Center, Amsterdam, the Netherlands, ${ }^{4}$ Department of Virology, Erasmus Medical Center Rotterdam, the Netherlands and ${ }^{5}$ Center for Experimental and Molecular Medicine, Academic Medical Center, Amsterdam, the Netherlands

Received: 4 November 2009 Accepted: 16 April 2010 Published: 16 April 2010

\section{References}

1. Sabin CA, Worm SW, Weber R, Reiss P, El-Sadr W, Dabis F, De Wit S, Law M, D'Arminio Monforte A, Friis-Moller N, Kirk O, Pradier C, Weller I, Phillips AN, Lundgren JD: Use of nucleoside reverse transcriptase inhibitors and risk of myocardial infarction in HIV-infected patients enrolled in the D:A:D study: a multi-cohort collaboration. Lancet 2008, 371:1417-26.

2. Use of nucleoside reverse transcriptase inhibitors and risk of myocardial infarction in HIV-infected patients. AIDS 2008, 22:F17-24

3. Obel N, Farkas DK, Kronborg G, Larsen CS, Pedersen G, Riis A, Pedersen C, Gerstoft J, Sorensen HT: Abacavir and risk of myocardial infarction in HIV-infected patients on highly active antiretroviral therapy: a population-based nationwide cohort study. HIV Med 2010, 11:130-6.

4. Benson CRH, Zheng E, Smurzynski M, Bosch R, Bastow B, Collier A, Schouten J: No association of abacavir use with risk of myocardial infarction or severe cardiovascular disease events: Results from ACTG A5001 [Abstract 721]. 16th Conference on Retroviruses and Opportunistic Infections 8-11 February 2009; Montreal

5. Brothers $\mathrm{CH}$, Hernandez JE, Cutrell AG, Curtis L, Ait-Khaled M, Bowlin SJ, Hughes SH, Yeo JM, Lapierre DH: Risk of myocardial infarction and abacavir therapy: no increased risk across 52 GlaxoSmithKlinesponsored clinical trials in adult subjects. J Acquir Immune Defic Syndr 2009, 51:20-8.

6. Hsue PY, Hunt PW, Wu Y, Schnell A, Ho JE, Hatano H, Xie Y, Martin JN, Ganz $P$, Deeks SG: Association of abacavir and impaired endothelial function in treated and suppressed HIV-infected patients. AIDS 2009.

7. Satchell COCE, Peace A, Cotter A, Sheehan G, Tedesco T, Doran P, Powderly W, Kenny D, Mallon P: Platelet hyper-reactivity in HIV-1infected patients on abacavir-containing ART [Abstract 151LB]. 16th Conference on Retroviruses and Opportunistic Infections 8-11 February 2009; Montreal

8. McComsey GSK, Patel P, Bellos N, Sloan L, Lackey P, Kumar P, SutherlandPhilips D, Yau L, Shaefer M: Similar reductions in markers of inflammation and endothelial activation after initiation of abacavir/ lamivudine or tenofovir/emtricitabine: The HEAT study [Abstract 732]. 16th Conference on Retroviruses and Opportunistic Infections 8-11 February 2009; Montreal. 
9. Palella PGS, Elion R, Kaplan R, Williams C, Landay A, Jacobson L, Tracy R: Inflammatory markers among abacavir and non-abacavir recipients in the Womens' Interagency HIV Study and the Multicenter AIDS Cohort Study [Abstract 150LB]. 16th Conference on Retroviruses and Opportunistic Infections 8-11 February 2009; Montreal.

10. Kristoffersen US, Kofoed K, Kronborg G, Benfield T, Kjaer A, Lebech AM: Changes in biomarkers of cardiovascular risk after a switch to abacavir in HIV-1-infected individuals receiving combination antiretroviral therapy. HIV Med 2009, 10:627-33.

11. Libby P, Ridker PM: Inflammation and atherosclerosis: role of C-reactive protein in risk assessment. Am J Med 2004, 116(Suppl 6A):9S-16S.

12. Pore N, Gupta AK, Cerniglia GJ, Maity A: HIV protease inhibitors decrease VEGF/HIF-1alpha expression and angiogenesis in glioblastoma cells. Neoplasia 2006, 8:889-95.

13. Sgadari C, Barillari G, Toschi E, Carlei D, Bacigalupo I, Baccarini S, Palladino C, Leone P, Bugarini R, Malavasi L, Cafaro A, Falchi M, Valdembri D, Rezza G, Bussolino F, Monini P, Ensoli B: HIV protease inhibitors are potent antiangiogenic molecules and promote regression of Kaposi sarcoma. Nat Med 2002, 8:225-32.

14. Eremina V, Jefferson JA, Kowalewska J, Hochster H, Haas M, Weisstuch J, Richardson C, Kopp JB, Kabir MG, Backx PH, Gerber HP, Ferrara N, Barisoni L, Alpers CE, Quaggin SE: VEGF inhibition and renal thrombotic microangiopathy. NEng/ J Med 2008, 358:1129-36.

15. Jong ELS, Meijers JCM, De Kruif MD, Ten Cate H, Buller HR, Mulder JW, Van Gorp ECM: The hemostatic balance in HIV-infected patients with and without antiretroviral therapy: Partial restoration with antiretroviral therapy. AIDS Patient Care STDs 2009, 23:1001-7.

16. ten Cate-Hoek AJ, Dielis AW, Spronk HM, van Oerle R, Hamulyak K, Prins $\mathrm{MH}$, ten Cate $\mathrm{H}$ : Thrombin generation in patients after acute deep-vein thrombosis. Thromb Haemost 2008, 100:240-5.

17. Hsue PL, Younes N, Martin J, Deeks S, Waters D: C-reactive protein levels in patients with HIV: A marker of cardiovascular risk or chronic infection? [Abstract 864]. 12th Conference on Retroviruses and Opportunistic Infections 22-25 February 2005; Boston .

doi: 10.1186/1742-6405-7-9

Cite this article as: Jong et al,, Markers of inflammation and coagulation indicate a prothrombotic state in HIV-infected patients with long-term use of antiretroviral therapy with or without abacavir AIDS Research and Therapy $2010,7: 9$

Submit your next manuscript to BioMed Centra and take full advantage of:

- Convenient online submission

- Thorough peer review

- No space constraints or color figure charges

- Immediate publication on acceptance

- Inclusion in PubMed, CAS, Scopus and Google Scholar

- Research which is freely available for redistribution

Submit your manuscript at www.biomedcentral.com/submit
C Biomed Central 